\title{
Biocompatible Supramolecular Catalytic One-Dimensional Nanofibers for Efficient Labeling of Live Cells
}

\author{
Mohammad Aref Khalily, ${ }^{\dagger}$ Gulcihan Gulseren, ${ }^{\dagger}$ Ayse B. Tekinay, ${ }^{*}{ }^{\dagger}$ and Mustafa O. Guler* ${ }^{\dagger}$ \\ ${ }^{\dagger}$ Institute of Materials Science and Nanotechnology, National Nanotechnology Research Center (UNAM), Bilkent University, \\ Ankara, Turkey 06800
}

\section{Supporting Information}

\begin{abstract}
Understanding complex cellular functions requires study and tracking of biomolecules such as proteins, glycans, and lipids in their natural environment. Herein, we report the first supramolecular nanocatalyst for bioorthogonal click reaction to label live cells. This biocompatible and biodegradable nanocatalyst was formed by self-assembled peptide nanofibers complexed with copper ions. The supramolecular nanocatalyst enhanced azide-alkyne cycloaddition reaction rate under physiological conditions and was shown to be useful for efficient bioorthogonal labeling of live cells.
\end{abstract}
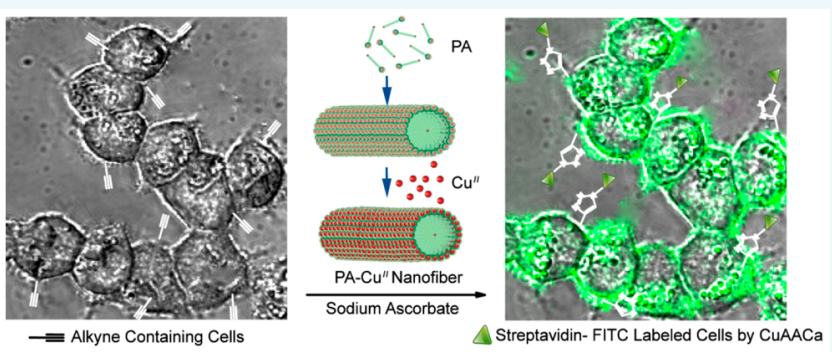

$\mathrm{U}$ nderstanding complex cellular functions requires study and tracking of biomolecules such as proteins, glycans, and lipids in their natural environment. A variety of bioorthogonal reactions such as ketone/hydroxylamine condensation, Staudinger ligation, strain promoted alkyne-azide cycloaddition (SPAAC), strain promoted alkyne-nitrone catalyzed cross coupling, Diels-Alder cycloaddition, and copper-catalyzed azide-alkyne cycloaddition ( $\mathrm{CuAACa}$ ) have been developed to label biomolecules in their native environment. ${ }^{1}$ Owing to low cytotoxicity and inertness of alkyne-azide functional groups under physiological conditions including excellent reaction kinetics, and high specificity, CuAACa has received great attention to label and specifically probe different biomolecules in living cells. ${ }^{2}$ However, a major problem of this reaction is the cytotoxicity of $\mathrm{Cu}^{\mathrm{I}}$, which causes the generation of reactive oxygen species (ROS) from $\mathrm{O}_{2}{ }^{3}{ }^{3}$ To overcome this problem, two different approaches have been developed. The first approach is to perform the strain promoted alkyne-azide cycloaddition (SPAAC) without using $\mathrm{Cu}^{\mathrm{I}}$ as catalyst. ${ }^{4}$ This method suffers from slow reaction kinetics. Even the fastest SPAAC is 10 times slower than the $\mathrm{Cu}^{\mathrm{I}}$-mediated one. ${ }^{5}$ Moreover, very hydrophobic and reactive cyclooctynes have pharmacokinetic problems in mice and can cause unwanted side reactions with endogenous nucleophiles such as thiols. ${ }^{6}$ Another approach is to design ligands, which coordinate to $\mathrm{Cu}^{\mathrm{I}}$ and enhance its biocompatibility.

Typical ligands include bathophenanthroline disulfonate disodium salt (BPS), ${ }^{7}$ 14,41 tris((1-benzyl-1H-1,2,3-triazol-4yl)methyl)amine (TBTA), ${ }^{8}$ tris-(hydroxypropyltriazolyl)-methylamine (THPTA), ${ }^{9}$ bis[(tertbutyltriazoyl) methyl $]-[(2-$ carboxymethyltriazoyl)methyl $]$ amine (BTTAA), ${ }^{10}$ and L-histidine. ${ }^{11}$ Despite promising results, it is still challenging to design biocompatible and biodegradable ligands that show excellent catalytic activity in complex living environment with minimal $\mathrm{Cu}^{\mathrm{I}}$ cytotoxicity.
In this work, we demonstrate the first supramolecular nanocatalyst, which has lower cytotoxicity and superior catalytic activity than molecular catalysts employed in bioorthogonal click reactions. We exploited the advantage of self-assembling peptide amphiphile (PA) molecules to construct biocompatible and biodegradable copper decorated supramolecular onedimensional nanofibers (PA-Cu $\left.{ }^{\mathrm{II}}\right)$ for efficient labeling of live cells (Scheme 1). Self-assembled peptide amphiphile nanofibers

Scheme 1. Schematic Representation of Labeling Live Cells by PA-Cu' ${ }^{\text {II }}$ Nanofibers
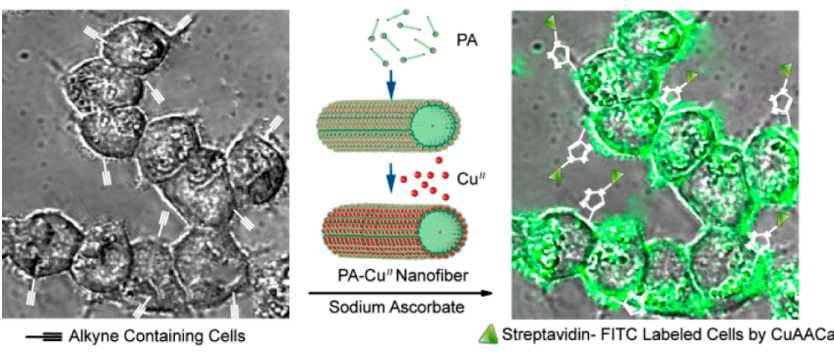

are a class of supramolecular polymers, which are produced by natural amino acids conjugated to a fatty acid. ${ }^{12}$ Due to their intrinsic biocompatibility, biodegradability, biofunctionality, rational design, and versatile functional groups, peptide amphiphiles have been widely used in tissue engineering and regenerative medicine applications. ${ }^{13}$ Inspired by multipurpose characteristics of self-assembling peptide amphiphiles; we have designed and synthesized a peptide amphiphile molecule, which

Received: August 7, 2015

Revised: October 8, 2015

Published: October 12, 2015 
has binding affinity for copper ions. The PA molecule with a sequence of Lauryl-VVAGHH-Am (Figure S1, see Supporting Information) was successfully synthesized by using standard solid-phase peptide synthesis (SPPS). (Figures S2-S3, see Supporting Information). We also synthesized a soluble Ac$\mathrm{HH}-\mathrm{Am}$ dipeptide as a nonassembling and copper binding part of the Lauryl-VVAGHH-Am molecule (Figures S4-S6, see Supporting Information).

The PA molecules consist of three regions (Figure S1, see Supporting Information). The lauryl moiety is required for hydrophobic collapse of the PA molecules in aqueous medium. Meanwhile, the peptide sequence containing valine and alanine residues promotes the formation of $\beta$-sheet structures. The two histidine residues serve as hydrophilic segment for dissolving the PA molecules in aqueous medium in addition to their high binding affinity for copper ions. ${ }^{14}$ When dissolved in water, the PA molecules aggregate due to noncovalent interactions. Critical aggregation concentration for Lauryl-VVAGHH-Am was calculated as less than $16 \mu \mathrm{M}$ (Figure S7, see Supporting Information). The circular dichroism (CD) spectrum of the PAs (Figure 1a) shows a positive peak at $200 \mathrm{~nm}$ and a negative
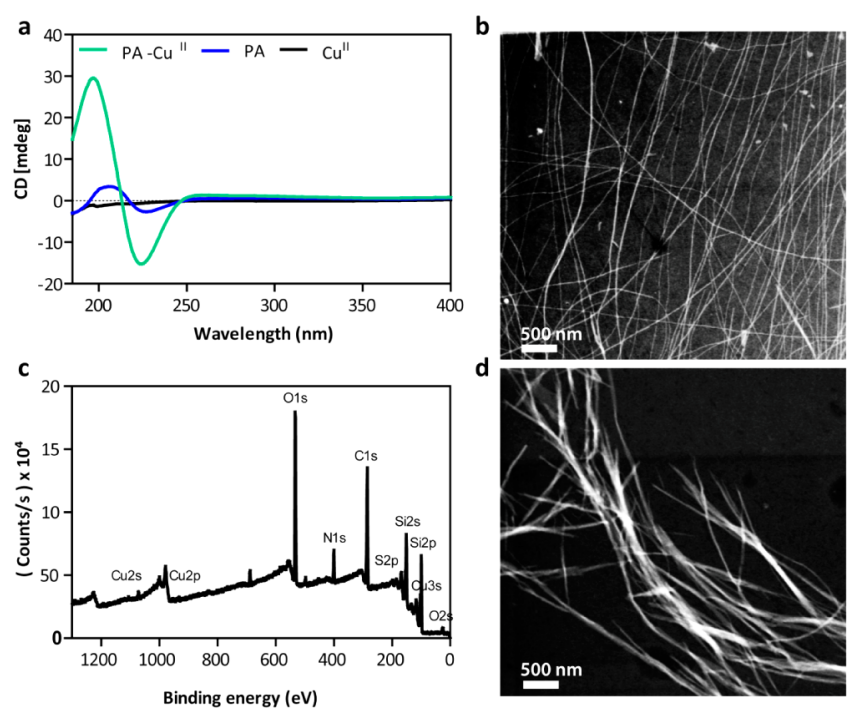

Figure 1. (a) CD analysis of PA and PA-Cu ${ }^{\mathrm{II}}$, (b) STEM image of the PA nanofibers, (c) XPS, and (d) STEM image of PA-Cu ${ }^{\text {II }}$ nanofibers.

peak at $223 \mathrm{~nm}$, which shows the presence of $\beta$-sheets. ${ }^{15}$ The PA molecules form supramolecular 1-D nanofibers as revealed by transmission electron microscopy (Figure 1b; Figure S8a-b, see Supporting Information) and scanning electron microscopy (Figure S8c-d, see Supporting Information). The supramolecular PA nanofibers have diameters of about $10 \mathrm{~nm}$ and lengths in microns. The surface of the supramolecular PA nanofibers was decorated with $\mathrm{Cu}^{\mathrm{II}}$ ions by simply mixing the PA and copper sulfate solutions (Figure S9, see Supporting Information). Upon mixing the solutions, a self-supporting PA$\mathrm{Cu}^{\mathrm{II}}$ gel was formed (Figure S9, see Supporting Information). The gel formation was further confirmed by oscillatory rheology analysis (Figure S10a-b) where the storage modulus $\left(G^{\prime}\right)$ was higher than loss modulus $\left(G^{\prime \prime}\right)$. Rapid gel formation shows the presence of interactions between PA molecules and the $\mathrm{Cu}^{\mathrm{II}}$ ions. This interaction was also proved by amplification in $\beta$-sheet intensity of PA-Cu ${ }^{\mathrm{II}}$ nanofibers (Figure $1 \mathrm{a}$ ).

The supramolecular PA-Cu ${ }^{\mathrm{II}}$ nanofibers were imaged by TEM and bundling of the nanofibers was observed (Figure 1d;
Figure S1la-b, see Supporting Information), which could be due to the cross-linking of PA nanofibers by $\mathrm{Cu}^{\mathrm{II}}$ ions. Likewise, the SEM image (Figure S11c, see Supporting Information) of $\mathrm{PA}-\mathrm{Cu}$ II nanofibers showed that the nanofibrous morphology was conserved. The energy-dispersive X-ray spectroscopy (EDS/SEM) of PA-Cu ${ }^{\mathrm{II}}$ verified the existence of the copper and sulfur species on the nanofibers (Figure S11d, see Supporting Information).

We measured the thermodynamic response of $\mathrm{Cu}^{\mathrm{II}}$ ion binding to peptide molecules by using isothermal titration calorimetry (ITC). To minimize the artifacts due to selfassembly of the PA molecules, we analyzed binding of dipeptide (Ac-HH-Am) molecule to $\mathrm{Cu}^{\mathrm{II}}$ ion. Binding properties of the single histidine to copper have straightforward interpretation, whereas inclusion of a second histidine introduces the possibility of cooperation in copper binding. In our case, two copper binding sites were observed similarly to previous studies. ${ }^{16}$ For the active site-metal interaction, ITC binding isotherms were best fitted by two sets of site mode with $K$ values: $K_{1}=\left(5.11 \times 10^{4}\right) \pm\left(3.36 \times 10^{4}\right) \mathrm{M}^{-1}$ and $K_{2}=(2.51 \times$ $\left.10^{3}\right) \pm\left(2.11 \times 10^{3}\right) \mathrm{M}^{-1}$ (Figure S12, see Supporting Information). Binding affinity ( $c$ values) of each site was calculated as $c_{1}=19.44$ and $c_{2}=7.75$, which could be considered moderate metal ion binding.

To further investigate the interactions between the PA molecules and copper ions, the $\mathrm{PA}-\mathrm{Cu}^{\mathrm{II}}$ gel was rinsed thoroughly with water to remove any unbound PA molecules and copper ions. Then the sample was freeze-dried to acquire a bluish powder of PA-Cu ${ }^{\mathrm{II}}$ (Figure S9, see Supporting Information). The X-ray photoelectron spectroscopy (XPS) analysis of $\mathrm{PA}-\mathrm{Cu}^{\mathrm{II}}$ powder revealed peaks at 934.5 and 167.1 $\mathrm{eV}$ (Figure 1C; and Figure S13, see Supporting Information), which corresponds to $\mathrm{Cu} 2 \mathrm{p}_{3 / 2}$ and $\mathrm{S} 2 \mathrm{p}$, respectively; these are assigned to $\mathrm{Cu}^{\mathrm{II}}$ and $\mathrm{S}{ }^{\mathrm{IV}}\left(\mathrm{CuSO}_{4}\right){ }^{17} \mathrm{We}$ also performed inductively coupled plasma mass spectrometry (ICP-MS) to determine the amount of copper in $\mathrm{PA}-\mathrm{Cu}{ }^{\mathrm{II}}$ powder (see Supporting Information). By analyzing the ICP-MS and elemental analysis results, we calculated that the PA molecule binds to copper ion at 1:1 ratio. These results proved the coordination of $\mathrm{CuSO}_{4}$ to PA nanofibers.

Bioorthogonal reactions must be performed in physiological conditions. Previously, catalyst activity was usually tested in a mixture of organic solvents and water utilized for labeling of biomolecules. ${ }^{10,11,18}$ Unlike those studies, we tested the activity of the supramolecular PA-Cu ${ }^{\text {II }}$ nanofibers under physiological conditions to obtain more realistic results. A typical Huisgen 1,3-dipolar cycloaddition reaction was designed where phenylacetylene and benzylazide were chosen as reactants, sodium ascorbate as reducing agent, and water as biological solvent (Table1). Since L-histidine-copper complex (His-Cu ${ }^{\mathrm{II}}$ ) showed the highest catalytic activity in bioorthogonal click reaction among other catalysts in the literature, ${ }^{11}$ we compared our supramolecular nanocatalyst (PA-Cu ${ }^{\mathrm{II}}$ nanofibers) with this complex.

His-Cu ${ }^{\text {II }}$ complex demonstrated a moderate conversion efficiency of $61 \%$ (Table 1). In addition, soluble dipeptide (Ac-HH-Am) complexed with $\mathrm{Cu}^{\mathrm{II}}$ ion $\left(\mathrm{HH}-\mathrm{Cu}^{\mathrm{II}}\right)$ also showed a moderate conversion efficiency of $65 \%$, while $\mathrm{PA}-\mathrm{Cu}^{\mathrm{II}}$ nanofibers demonstrated a tremendous conversion efficiency of $95 \%$ under the same conditions (Table 1). There are two possible explanations for this striking difference in the reaction efficiencies where all catalysts have histidine as copper binding sites. Assembly of catalytic sites within a nanostructured 
Table 1. Comparison of Catalyst Efficiency in $\mathrm{CuAACa}^{a}$

\begin{tabular}{|c|c|c|c|c|}
\hline & & $\begin{array}{l}\text { Catalyst (1 mol \%) } \\
\text { (+)-sodium-L-ascorba }\end{array}$ & mol \%) & $N_{n}=n$ \\
\hline reaction no. & catalyst & temperature & time & conversion $\%^{b}$ \\
\hline 1 & $\mathrm{CuSO}_{4}$ & $37^{\circ} \mathrm{C}$ & $12 \mathrm{~h}$ & 54 \\
\hline 2 & His-Cu ${ }^{\text {II }}$ & $37^{\circ} \mathrm{C}$ & $12 \mathrm{~h}$ & 61 \\
\hline 3 & $\mathrm{HH}-\mathrm{Cu}^{\mathrm{II}}$ & $37^{\circ} \mathrm{C}$ & $12 \mathrm{~h}$ & 65 \\
\hline 4 & $\mathrm{PA}-\mathrm{Cu}^{\mathrm{II}}$ & $37^{\circ} \mathrm{C}$ & $12 \mathrm{~h}$ & 95 \\
\hline 5 & $\mathrm{PA}-\mathrm{Cu}^{\mathrm{II}}$ & $25^{\circ} \mathrm{C}$ & $24 \mathrm{~h}$ & 81 \\
\hline
\end{tabular}

${ }^{a}$ Reaction conditions: benzylazide $(0.285 \mathrm{mmol})$, phenylacetylene $(0.285 \mathrm{mmol})$, catalyst $(1 \mathrm{~mol} \%)$, sodium ascorbate $(0.0285 \mathrm{mmol}, 10$ mol \%), water $(3 \mathrm{~mL}) .{ }^{b}$ Reaction conversions were determined by GC-MS (Figure S16-S25, ESI).

environment on PA nanofibers could show positive cooperativity, thus increased reaction rates. ${ }^{19}$ Moreover, two histidine motifs are in close proximity to hydrophobic amino acids such as glycine, alanine, and valine (Figure S1, see Supporting Information). When assembled into nanofibers, these amino acids could create a favorable hydrophobic environment for the reactants. Hence, the chance of gathering of catalytic sites with reactants was increased on PA nanofibers; as a consequence, the rate of the reaction was improved. It is worth mentioning that $\mathrm{PA}-\mathrm{Cu}^{\mathrm{II}}$ nanofibers can catalyze azide-alkyne cycloaddition significantly in green conditions (at room temperature in neat water, Table 1, reaction no 5). During the reaction, pale blue $\mathrm{PA}-\mathrm{Cu}{ }^{\mathrm{II}}$ color changes to yellowish green, which demonstrates the reduction of $\mathrm{Cu}^{\mathrm{II}}$ to $\mathrm{Cu}^{\mathrm{I}} .^{17}$

We have conducted a series of organic syntheses of essential molecules for labeling. A multisynthetic pathway was followed to introduce azide functional group to D-biotin (biotin-azide, see Supporting Information) and alkyne functional group to Dmannose amine ( $\mathrm{Ac}_{4} \mathrm{ManNAl}$, see Supporting Information). Intermediate molecules and end products were characterized by NMR (Figures S26-35, see Supporting Information) and high resolution mass spectrometry (Figures S36-40, see Supporting Information). All molecules were synthesized according to methods in the literature with slight modifications.

The copper-catalyzed click chemistry method offers a bioorthogonal strategy that can label live cells in a complex environment, allowing the function and dynamics of target biomolecules to be monitored in living organisms. Here, an unnatural sialic acid precursor bearing a bioorthogonal functional group (alkyne functionalized sugar ( $\left.\mathrm{Ac}_{4} \mathrm{ManNAl}\right)$ ) was introduced to living cells by using biosynthetic pathways and a chemical tag (biotin-azide) was subsequently attached to the alkyne-bearing sialic acid group by CuAACa. The labeling process was then completed with the addition of a streptavidin-fluorescein (FITC) conjugate. ${ }^{20}$ Copper-coordinating ligands used for dynamic imaging studies must meet certain criteria; such as high binding affinity for copper ions, biocompatibility, biodegradability, and the ability to perform their reactions rapidly under physiological conditions. In view of these requirements, we used PA molecules derived from natural amino acids as a ligand to coordinate and stabilize the $\mathrm{Cu}^{\mathrm{I}}$ oxidation state and to obtain improved reaction kinetics and minimized cytotoxicity. Cytotoxicity resulting from oxidative damage is one major drawback of copper catalysts for bioorthogonal labeling reactions. Owing to the stabilization of $\mathrm{Cu}^{\mathrm{I}}$, the peptide ligand can prevent the formation of undesired byproducts and minimize the oxidative damage against target biomolecules and cells. In addition to reduced toxicity, biocompatibility, and biodegradability, another important feature of the supramolecular nanofiber-based catalysis is the availability of a large number of active sites on a small area, which enhances reactivity by better facilitating surfacesubstrate interactions.

To evaluate the potential of PA-Cu ${ }^{\mathrm{I}}$ nanofibers (PA-Cu ${ }^{\mathrm{II}}+$ sodium ascorbate) in cell labeling applications, variable concentrations of the PA-Cu ${ }^{\mathrm{I}}$ nanocatalyst $(3-0.125 \mathrm{mM})$ were administered to MCF-7 (breast adenocarcinoma) cells. MCF-7 cells were treated with $\mathrm{Cu}^{\mathrm{I}}$ ions $\left(\mathrm{CuSO}_{4}\right.$ and sodium ascorbate) in the absence of ligand as positive control, and the effect of ligand incorporation on viability was tested. After $6 \mathrm{~h}$ of catalyst exposure, PA-Cu ${ }^{\mathrm{I}}$ nanofibers were found to display significantly lower cytotoxicity compared to copper-alone samples for all copper concentrations (Figure 2a). Toxicities

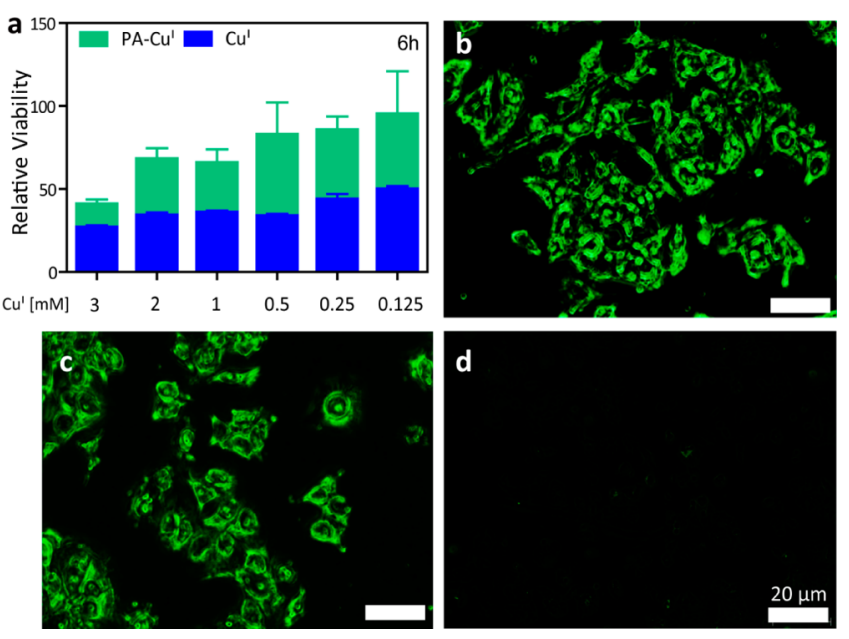

Figure 2. Viability of MCF-7 cells in the presence of PA-Cu $\mathrm{Cu}^{\mathrm{I}}$ and $\mathrm{Cu}^{\mathrm{I}}$ (a); microscopic analysis of fixed cells labeled with PA-Cu ${ }^{\mathrm{I}}$ nanofibers

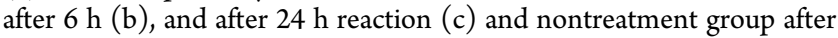
$24 \mathrm{~h}$ reaction $(\mathrm{d})$. (Scale bars $=20 \mu \mathrm{m}$.)

of PA-Cu ${ }^{\mathrm{I}}$ nanofibers were also found to be lower than $\mathrm{Cu}^{\mathrm{I}}$-only controls over extended exposure times ( $24 \mathrm{~h}$ ) (Figure S41, see Supporting Information). In previous bioorthogonal labeling studies with small molecule ligands, toxicity was tested in the presence of $\mathrm{Cu}^{\mathrm{II}}$-ligand complexes or lower copper concentrations. ${ }^{10,11}$ However, $\mathrm{Cu}^{\mathrm{II}}$ is found in the serum as an essential metal and is less toxic than $\mathrm{Cu}^{\mathrm{I}}$, which is the main ingredient of the click reaction mixture administered to cells. Our PA-Cu ${ }^{\mathrm{I}}$ nanocatalyst approach allows the use of higher $\mathrm{Cu}^{\mathrm{I}}$ concentrations for click chemistry, which makes PA nanofiber-based click catalysts promising for effective catalysis in the biological environments. Modification of cell membranes by $\mathrm{Ac}_{4} \mathrm{ManNAl}$ was verified and labeling reaction duration was optimized by using fixed MCF-7 cells. Cells were incubated with $\mathrm{Ac}_{4} \mathrm{ManNAl}$ for 3 days to introduce alkyne residues to cell surface sialyl glycoconjugates, and fixed with cold acetone. The acetylated form of the alkynyl sugar was administered to MCF7 cells since acetylation enhances cellular uptake compared to free sugars. ${ }^{21}$ Following $\mathrm{Ac}_{4} \mathrm{ManNAl}$ incorporation, MCF-7 cells bearing alkyne sialic acid residues were reacted with biotin-azide for $6 \mathrm{~h}$ in the presence of PA-Cu${ }^{\mathrm{I}}$ nanofibers, using a reaction mixture composed of biotin azide, $\mathrm{PA}-\mathrm{Cu}^{\mathrm{II}}$, and sodium ascorbate. 
The reaction mixture treated MCF-7 cells showed a strong labeling signal following the attachment of the biotin residue and staining with a fluorescent streptavidin-FITC probe. Cells treated with $\mathrm{Cu}^{\mathrm{I}}$-only were also labeled, while nontreated control groups were not labeled in the presence of the fluorescent probe (Figure $2 b-d$; Figure S42, see Supporting Information). This result suggests that alkynyl-tagged mannose moieties were incorporated into cell glycans and could function as chemical tags for PA-Cu ${ }^{\mathrm{I}}$ complex-mediated specific labeling after $6 \mathrm{~h}$ of reaction. After establishing optimum reaction times and $\mathrm{PA}-\mathrm{Cu}^{\mathrm{I}}$ nanofiber concentrations on fixed cells, we extended our study to the labeling of glycans in living cells. A bioorthogonal cell tracking experiment was carried out using the same procedure used for fixed cell labeling experiments, except that the cells were not fixed prior to the experiment. Labeling efficacy was monitored with confocal microscopy imaging following $\mathrm{CuAACa}$ reaction and fluorescent probe conjugation.

Fluorescence microscopy observations demonstrated that alkyne-tagged glycoconjugates are able to successfully modify MCF-7 cells and that PA-Cu ${ }^{\mathrm{I}}$ nanofiber administered group exhibited fluorescence levels above $\mathrm{Cu}^{\mathrm{I}}$-only group and nontreated cells, suggesting that the labeling of $\mathrm{Ac}_{4} \mathrm{ManNAl}$ is specific and $\mathrm{PA}-\mathrm{Cu}$ nanofibers could mediate adequate livecell labeling reaction (Figure $3 a-c$ ). The labeling efficiency of
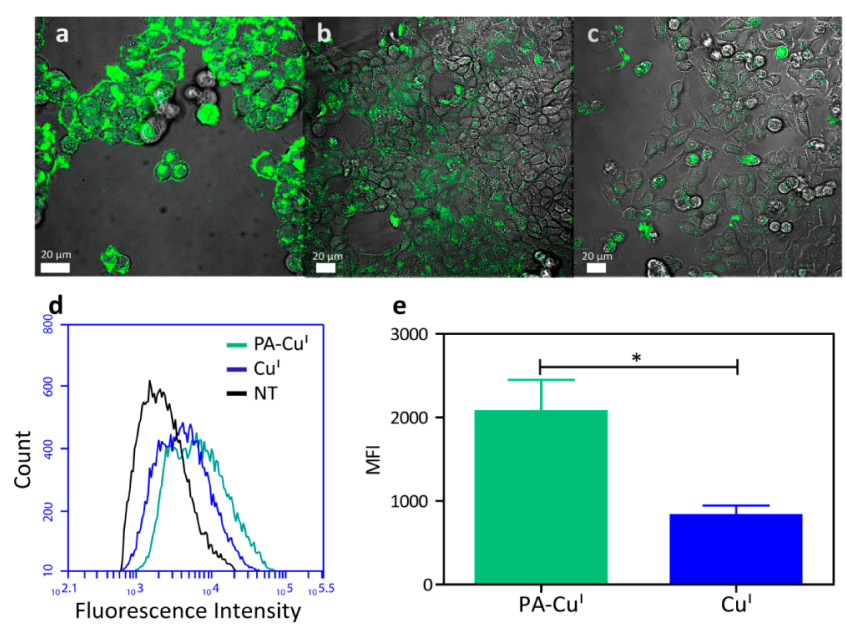

Figure 3. Confocal microscopy images of labeled cells with $\mathrm{PA}-\mathrm{Cu}^{\mathrm{I}}$ nanofibers $(\mathrm{a}), \mathrm{Cu}^{\mathrm{I}}(\mathrm{b})$, and nontreated (c) groups after $6 \mathrm{~h}$ reaction. Flow cytometry analysis of MCF-7 cells (green histogram, cells treated with $\mathrm{PA}-\mathrm{Cu}^{\mathrm{I}}$; blue histogram, cells treated with $\mathrm{Cu}^{\mathrm{I}}$; black histogram, nontreated cells) (d). Comparison of cell labeling efficiency by flow cytometry (e). To quantify labeling signals, the mean FITC intensities were calculated for $>10000$ cells for each condition, averaged, and compared. (Mean \pm SEM.)

PA- $\mathrm{Cu}^{\mathrm{I}}$ nanofibers was also evaluated through flow cytometry analysis of live cells treated with the PA-Cu${ }^{\mathrm{I}}$ complex or $\mathrm{Cu}^{\mathrm{I}}$ in the presence and absence of ligands. The background signal was excluded by the extraction of the emission signal of nontreated groups in order to facilitate comparison among catalysts. Consistent with the results obtained from confocal microscopy analysis, PA-Cu ${ }^{\mathrm{I}}$ nanofibers yielded higher labeling efficiency when compared to the $\mathrm{Cu}^{\mathrm{I}}$-only group (Figure $3 \mathrm{~d}, \mathrm{e}$ ).

In summary, we demonstrated the first supramolecular nanocatalyst, which was used in bioorthogonal click reaction for labeling of live cells. The nanocatalyst was fabricated by biocompatible and biodegradable supramolecular peptide amphiphile nanofibers. This novel supramolecular nanocatalyst not only reduced the cytotoxicity of $\mathrm{Cu}^{\mathrm{I}}$ ions, but also enhanced the reaction yields under physiological conditions. This novel labeling approach offers a promising method for studying biomolecular dynamics and functions in cells and living organisms and will open new directions in bioorthogonal chemistry field.

\section{ASSOCIATED CONTENT}

\section{S Supporting Information}

The Supporting Information is available free of charge on the ACS Publications website at DOI: 10.1021/acs.bioconjchem.5b00443.

Experimental details and additional figures (PDF)

\section{AUTHOR INFORMATION}

\section{Corresponding Authors}

*E-mail: atekinay@unam.bilkent.edu.tr.

*E-mail: moguler@unam.bilkent.edu.tr.

\section{Author Contributions}

M.A.K. synthesized the materials and performed their characterizations. G.G. performed in vitro cell culture studies. M.O.G. and A.B.T. designed and analyzed the experiments. All authors contributed to analysis of the results and writing of the manuscript.

Notes

The authors declare no competing financial interest.

\section{ACKNOWLEDGMENTS}

We thank TUBITAK 112 T602 and $114 \mathrm{Z728}$ for financial support.

\section{REFERENCES}

(1) Lang, K., and Chin, J. W. (2014) Bioorthogonal reactions for labeling proteins. ACS Chem. Biol. 9 (1), 16-20.

(2) Boyce, M., and Bertozzi, C. R. (2011) Bringing chemistry to life. Nat. Methods 8 (8), 638-42.

(3) Hong, V., Steinmetz, N. F., Manchester, M., and Finn, M. G. (2010) Labeling Live Cells by Copper-Catalyzed Alkyne-Azide Click Chemistry. Bioconjugate Chem. 21 (10), 1912-1916.

(4) Jewett, J. C., and Bertozzi, C. R. (2010) Cu-free click cycloaddition reactions in chemical biology. Chem. Soc. Rev. 39 (4), 1272-9.

(5) Uttamapinant, C., Tangpeerachaikul, A., Grecian, S., Clarke, S., Singh, U., Slade, P., Gee, K. R., and Ting, A. Y. (2012) Fast, cellcompatible click chemistry with copper-chelating azides for biomolecular labeling. Angew. Chem., Int. Ed. 51 (24), 5852-6.

(6) Chang, P. V., Prescher, J. A., Sletten, E. M., Baskin, J. M., Miller, I. A., Agard, N. J., Lo, A., and Bertozzi, C. R. (2010) Copper-free click chemistry in living animals. Proc. Natl. Acad. Sci. U. S. A. 107 (5), $1821-1826$.

(7) Sen Gupta, S., Kuzelka, J., Singh, P., Lewis, W. G., Manchester, M., and Finn, M. G. (2005) Accelerated bioorthogonal conjugation: a practical method for the ligation of diverse functional molecules to a polyvalent virus scaffold. Bioconjugate Chem. 16 (6), 1572-9.

(8) Chan, T. R., Hilgraf, R., Sharpless, K. B., and Fokin, V. V. (2004) Polytriazoles as copper(I)-stabilizing ligands in catalysis. Org. Lett. 6 (17), 2853-2855.

(9) Hong, V., Presolski, S. I., Ma, C., and Finn, M. G. (2009) Analysis and optimization of copper-catalyzed azide-alkyne cycloaddition for bioconjugation. Angew. Chem., Int. Ed. 48 (52), 9879-83.

(10) Besanceney-Webler, C., Jiang, H., Zheng, T. Q., Feng, L., del Amo, D. S., Wang, W., Klivansky, L. M., Marlow, F. L., Liu, Y., and Wu, P. (2011) Increasing the Efficacy of Bioorthogonal Click 
Reactions for Bioconjugation: A Comparative Study. Angew. Chem., Int. Ed. 50 (35), 8051-8056.

(11) Kennedy, D. C., McKay, C. S., Legault, M. C. B., Danielson, D. C., Blake, J. A., Pegoraro, A. F., Stolow, A., Mester, Z., and Pezacki, J. P. (2011) Cellular Consequences of Copper Complexes Used To Catalyze Bioorthogonal Click Reactions. J. Am. Chem. Soc. 133 (44), 17993-18001.

(12) Ulijn, R. V., and Smith, A. M. (2008) Designing peptide based nanomaterials. Chem. Soc. Rev. 37 (4), 664-675.

(13) Zhao, X. B., Pan, F., Xu, H., Yaseen, M., Shan, H. H., Hauser, C. A. E., Zhang, S. G., and Lu, J. R. (2010) Molecular self-assembly and applications of designer peptide amphiphiles. Chem. Soc. Rev. 39 (9), 3480-3498.

(14) Albada, H. B., Soulimani, F., Weckhuysen, B. M., and Liskamp, R. M. J. (2007) Scaffolded amino acids as a close structural mimic of type-3 copper binding sites. Chem. Commun. 46, 4895-4897.

(15) Ong, Z. Y., Gao, S. J., and Yang, Y. Y. (2013) Short Synthetic beta-Sheet Forming Peptide Amphiphiles as Broad Spectrum Antimicrobials with Antibiofilm and Endotoxin Neutralizing Capabilities. Adv. Funct. Mater. 23 (29), 3682-3692.

(16) Davies, P., McHugh, P. C., Hammond, V. J., Marken, F., and Brown, D. R. (2011) Contribution of Individual Histidines to Prion Protein Copper Binding. Biochemistry 50 (50), 10781-10791.

(17) Yamada, Y. M. A., Sarkar, S. M., and Uozumi, Y. (2012) Amphiphilic Self-Assembled Polymeric Copper Catalyst to Parts per Million Levels: Click Chemistry. J. Am. Chem. Soc. 134 (22), 92859290.

(18) Bevilacqua, V., King, M., Chaumontet, M., Nothisen, M., Gabillet, S., Buisson, D., Puente, C., Wagner, A., and Taran, F. (2014) Copper-chelating azides for efficient click conjugation reactions in complex media. Angew. Chem., Int. Ed. 53 (23), 5872-6.

(19) (a) Guler, M. O., and Stupp, S. I. (2007) A self-assembled nanofiber catalyst for ester hydrolysis. J. Am. Chem. Soc. 129 (40), 12082-3. (b) Singh, N., Conte, M. P., Ulijn, R. V., Miravet, J. F., and Escuder, B. (2015) Insight into the esterase like activity demonstrated by an imidazole appended self-assembling hydrogelator. Chem. Commun. 51 (67), 13213-13216.

(20) Hsu, T. L., Hanson, S. R., Kishikawa, K., Wang, S. K., Sawa, M., and Wong, C. H. (2007) Alkynyl sugar analogs for the labeling and visualization of glycoconjugates in cells. Proc. Natl. Acad. Sci. U. S. A. 104 (8), 2614-9.

(21) (a) Jacobs, C. L., Yarema, K. J., Mahal, L. K., Nauman, D. A., Charters, N. W., and Bertozzi, C. R. (2000) Metabolic labeling of glycoproteins with chemical tags through unnatural sialic acid biosynthesis. Methods Enzymol. 327, 260-275. (b) Sarkar, A. K., Fritz, T. A., Taylor, W. H., and Esko, J. D. (1995) Disaccharide uptake and priming in animal cells: inhibition of sialyl Lewis $\mathrm{X}$ by acetylated Gal beta $1->$ 4GlcNAc beta-O-naphthalenemethanol. Proc. Natl. Acad. Sci. U. S. A. 92 (8), 3323-7. 